\title{
Transcatheter aortic valve replacement: is anesthesiologic management linked to surgical outcomes?
}

\author{
Chiara Candela, Annalaura Di Pumpo, Alessandro Centonze, Fabrizio Cucciniello, Domenico Sarubbi, \\ Felice Eugenio Agrò
}

Department of Anesthesiology, Università Campus Bio-Medico di Roma, Rome 00128, Italy.

Correspondence to: Dr. Chiara Candela, Department of Anesthesiology, Università Campus Bio-Medico di Roma, Rome 00128, Italy. E-mail: c.candela@unicampus.it

\begin{abstract}
How to cite this article: Candela C, Di Pumpo A, Centonze A, Cucciniello F, Sarubbi D, Agrò FE. Transcatheter aortic valve replacement: is anesthesiologic management linked to surgical outcomes? Vessel Plus 2018;2:28. http://dx.doi.org/10.20517/2574-1209.2018.31
\end{abstract}

Received: 14 May 2018 First Decision: 25 Jul 2018 Revised: 7 Sep 2018 Accepted: 7 Sep 2018 Published: 29 Sep 2018

Science Editors: Mario F. L. Gaudino, Cristiano Spadaccio Copy Editor: Yuan-Li Wang Production Editor: Zhong-Yu Guo

\begin{abstract}
Aortic valve replacement (AVR) is the current standard treatment for severe aortic stenosis, nonetheless, many patients are not suitable to AVR because of high risk related to advanced age, impaired cardiac function, or comorbidities. Given these considerations, transcatheter aortic valve replacement or implantation (TAVR or TAVI) has emerged in the last decade as an alternative to surgery and has become the treatment of choice for severe aortic stenosis in patients with prohibitive surgical risk. In the context of this kind of hybrid procedure, the anesthesiologist plays a central role because the choice of anesthetic technique is strongly related to clinical features of the patients and technical considerations, which must be discussed collegially with the surgeons. The choice of anesthesiologic management is different among hospitals, but it is generally based on preoperative comorbidities, procedural approach used for TAVR and even hospital logistic. Some centers used to perform TAVR under general anesthesia (GA), some else under local anesthesia plus sedation (LAS), some of them start their TAVR program under GA, but convert in LAS when the team get enough experience. Also, anesthesiologists involved in TAVR procedures must be part of a "heart team", and should be confident with anesthesia for cardiovascular surgery, mechanical circulatory support, and with transesophageal echocardiography. The aim of this article is to provide a general overview about anesthetic techniques in TAVR and to evaluate pathways for future researches.
\end{abstract}

Keywords: Transcatheter aortic valve implantation, anesthesia, aortic valve disease 


\section{INTRODUCTION}

Aortic stenosis is the most common and dangerous cardiac valvular disease, which a reported incidence of $2 \%-4 \%$ of patients over 65 years $^{[1,2]}$. Aortic valve replacement (AVR) is the current standard treatment for severe aortic stenosis ${ }^{[3]}$, nonetheless, many patients are not suitable to AVR because of high risk related to advanced age, impaired cardiac function, relevant comorbidities such as chronic kidney disease or chronic obstructive pulmonary disease. In addition, heavily calcified aortas, previous mediastinal radiation, and redo valvular surgery expose patients to a prohibitive risk for standard AVR. Given these considerations, transcatheter aortic valve replacement or implantation (TAVR or TAVI) has emerged in the last decade as an alternative to surgery and has become the treatment of choice for severe aortic stenosis in patients with prohibitive surgical risk $^{[4-6]}$. The goal of this procedure is minimizing surgical trauma by avoiding sternotomy, aortotomy, cardiopulmonary bypass (CPB) and by implanting the prosthetic valve on beating heart, thereby avoiding cardiac arrest, in order to decrease perioperative risks and improve patient outcomes $^{[7]}$. Depending on patient characteristics, TAVR can be performed using different access sites including transfemoral (TF), trans-subclavian/trans-axillary, transaortic, or transapical approaches ${ }^{[8-10]}$. The most commonly used approach to performing TAVR is the TF approach by retrograde deployment of the valve passing through the ascending aorta. Most of the centers prefer TF approach because it is less invasive and is associated to a reduced percentage of cardiac related complications, therefore it continues to be the main approach used on patients without severe vascular disease ${ }^{[11]}$. Alternative access sites are used on patients with severe peripheral vascular disease and short vessel segments with iliac-femoral arteries diameters $<7 \mathrm{~mm}^{[12,13]}$.

In the context of this kind of hybrid procedure, the anesthesiologist plays a central role because the choice of anesthetic technique is strongly related to clinical features of the patients and technical considerations, which must be discussed collegially with the operators. The most important consideration for the anesthesiologist member of the care team is the type of anesthesia most suited for the patient. The choice of anesthesiologic management is different among hospitals, but it is generally based on preoperative comorbidities, procedural approach used for TAVR and even hospital logistics ${ }^{[14-18]}$. Some centers used to perform TAVR under general anesthesia (GA), some else under local anesthesia with a mild sedation (LAS), some of them start their TAVR program under GA, but convert in LAS when the team get enough experience. The aim of the anesthesiologist should be to provide less-invasive anesthesia/analgesia without compromising the safety or comfort of the patient. The aim of this article is to provide a general overview about anesthetic techniques in TAVR and to evaluate pathways for future researches.

\section{FROM AVR TO TAVR... AND FROM GA TO LAS}

Although GA is considered mandatory in case of transapical or transaortic approach, there has recently been a significant increase in literature showing the safety and efficacy of local anesthesia with LAS compared with GA when TF approach is performed ${ }^{[19,20]}$. At the beginning of a TAVR program, most centers initially chose to provide GA for this procedure, but as the team developed with enough experience and confidence with the procedure, many hospitals started to convert GA in LAS. Actually, the preferred anesthetic management is equally split among centers providing GA vs. sedation for TAVR ${ }^{[21]}$.

The induction of GA can be performed with a variety of agents, often with a reduced dosage and a very slow administration because of advanced age and decreased cardiac function. Surgical stimulation is not much painful, so the procedure does not need elevated dosage of opioids. Inhalational agents may have some advantages on myocardial protection ${ }^{[22-26]}$ thanks to a pharmacological preconditioning and postconditioning action. Studies performed on patients undergoing coronary artery bypass graft (CABG) surgery, showed lower postoperative values of cardiac troponin because of the cardioprotective effect of inhalational agents. Short-acting drugs, such as Remifentanil, that are rapidly cleared are preferred to 
Table 1. Comparison of general anesthesia (GA) and local anesthesia with a mild sedation (LAS) in TAVR

\begin{tabular}{|c|c|c|c|}
\hline \multicolumn{2}{|r|}{ GA } & \multicolumn{2}{|c|}{ LAS } \\
\hline Advantage & Disadvantages & Advantages & Disadvantages \\
\hline $\begin{array}{l}\text { Safety in starting TAVR } \\
\text { program }\end{array}$ & $\begin{array}{l}\text { Myocardial depression due to } \\
\text { anesthetic drugs }\end{array}$ & Hemodynamic stability & Patient discomfort \\
\hline $\begin{array}{l}\text { Safety in predicted difficult } \\
\text { airway }\end{array}$ & $\begin{array}{l}\text { Weaning from mechanical } \\
\text { ventilation }\end{array}$ & Reduced in-hospital stay & Not safe in predicted difficult airway \\
\hline $\begin{array}{l}\text { Safety in expected technical } \\
\text { complications }\end{array}$ & $\begin{array}{l}\text { Increased in-hospital stay and } \\
\text { ICU stay }\end{array}$ & Reduced ICU stay & Not safe in starting TAVR program \\
\hline Patient immobility & $\begin{array}{l}\text { More invasive (catheterization, } \\
\text { CVC, mechanical ventilation) }\end{array}$ & Reduced delirium & $\begin{array}{l}\text { Not safe in expected technical } \\
\text { complications }\end{array}$ \\
\hline Easy use of TEE & & $\begin{array}{l}\text { Less invasive (catheterization, CVC, } \\
\text { mechanical ventilation) }\end{array}$ & \\
\hline
\end{tabular}

TAVR: transcatheter aortic valve replacement; TEE: tranesophageal ecocardiography; ICU: intensive care unit; CVC central venous catheter

ease extubation at the end of the procedure. Airway control is performed by endotracheal intubation. Any supraglottic device is not advised because of the use of transesophageal echocardiography.

The reason why most centers initially perform TAVR under GA is the safety of anesthesiologic management and the easier management of procedural complications. TAVR has already been demonstrated to be an effective and safe procedure, but it may have important and very dangerous complications leading to true catastrophic events that are often life threatening such as coronary artery occlusion, annular rupture, prosthesis embolization, major vascular injuries, cardiac tamponade, aortic dissection, and/or ventricular perforation $^{[27,28]}$.

Although conversion to GA because of emergency complications is not common, ranging from $2 \%-5 \%{ }^{[2-32]}$, most of these events cause serious hemodynamic instability and any delay of ventilation can worsen significantly patient outcome.

Similar considerations are needed for major vascular injuries such as vascular dissection, vascular perforation, and hematoma often requiring blood transfusions. Even in these circumstances conversion to GA may be necessary.

Further advantages of performing TAVR under GA include patient immobility during valve positioning, reduction of breathing artifacts, patient tolerability for the length of the procedure, but above all, facilitating the use of tranesophageal ecocardiography (TEE). TEE is an useful instrument during the procedure to assist optimal valve placement and prompt recognition of complication such as tamponade or interference with mitral valve. TEE guides the advancement of guidewires and the delivery system and allows to evaluate the effects of the balloon aortic valvuloplasty and the position of the prosthesis at deployment, also it allows to perform a post-implant valve assessment to identify residual regurgitation or paravalvular leaks. Also, 3D TEE may give additional information about structures, catheters and device $^{[33,34]}$.

Whereas many institutions still perform TAVR under GA, many clinicians in recent years have proposed local anesthesia with or without mild sedation. Several drugs and compounds have been used as monotherapy or in combination for sedating patients during TAVR, including dexmedetomidine, remifentanil, midazolam, ketamine and propofol ${ }^{[15,31,35-39]}$.

Local anesthesia combined with conscious sedation provides multiple advantages compared with GA [Table 1]. These benefits are especially noticeable in an old age and a high level of frailty patient 
population. Indeed, anesthetic drugs may have depressant effects on myocardial tissue and vasodilatory activity resulting in hemodynamic instability, hypotension and bradycardia which may reduce vital organ perfusion pressure, leading to several postoperative complications such as neurological deficits, myocardial ischemia or renal disfunction ${ }^{[40,41]}$. The use of LAS as an anesthetic choice for TAVR permits to avoid collateral effects of general anesthetics, minimizing hemodynamic instability.

It is furthermore not surprising that using LAS decreases pulmonary complications such as respiratory failure and pneumonia by avoiding mechanical ventilation ${ }^{[28]}$.

Also, has been showed a significant reduction in postprocedural delirium, which has been showed to prolong in-hospital stay and impair long-term survival. Delirium after TAVR occurs early in the postoperative period, with a percentage around $13 \%$. Patients who developed postprocedural delirium more frequently underwent non-TF procedures under $\mathrm{GA}^{[42]}$.

\section{REGISTRY DATA ANALYSIS}

Since LAS has emerged as an alternative to GA, many groups have conducted systematic reviews and metanalysis in order to determine if the change in anesthetic management has modified the outcome.

In the French Aortic National CoreValve and Edwards 2 (FRANCE 2) registry, data from 2326 patients who underwent TF-TAVR were analyzed, comparing patients receiving GA $v s$. LAS ${ }^{[43]}$. This analysis highlighted similar clinical outcomes for GA and LAS about procedure success, 30-day and 1-year survival rates, incidence of complications such as myocardial infarction, stroke, and vascular and bleeding complications. The only significant difference in outcomes was that there is a higher incidence of postprocedural aortic regurgitation in the LAS group. This result is probably due to the less frequent use of TEE support during TAVR under LAS.

However, the new model of Edwards valve minimizes postoperative aortic regurgitation, indeed further studies demonstrated that residual postprocedural aortic regurgitation is completely absent or insignificant in patients implanted with this third-generation valve under $\operatorname{LAS}^{[4,45]}$.

Data from the Italian CoreValve registry also analyzed a cohort of 1316 patients to assess the safety and non-inferiority of LAS $v s$. GA. The authors demonstrated that, in experienced centers which have gone over their initial learning period with TAVR, LAS can be performed safely with good clinical outcomes, with no significant difference in myocardial infarction, stroke or mortality than GA group ${ }^{[27]}$.

In a recent review the authors screened publications (randomized controlled trials and observational studies) published between 1 January 2006 and 26 June 2016 that compared LAS to GA in an adult study population undergoing TAVR, to identify the potential favorable effects of LAS compared with GA. They analyzed differences between LAS and GA in terms of 30-day mortality, in-hospital mortality and other endpoints that address safety and complications rates ${ }^{[46]}$. The authors showed no significant difference in the 30-day mortality rate among the two groups. Similarly, the in-hospital mortality rate did not demonstrate any significant difference between the study groups. Instead, the authors revealed a significant decrease in both intraprocedural and postprocedural catecholamine need in the LAS group. During TAVR, $31 \%$ of the LAS group received catecholamines, in contrast, the rate was $65.0 \%$ in the GA group.

As explained previously, this result in LAS group is probably due to the absence of hemodynamic effects of general anesthetics, such as vasodilation and myocardial depression. Regarding catecholamine administration, inotropes are more used than vasopressors, since patients suitable for TAVR often have a 
depressed cardiac function which is the main factor of hemodynamic instability.

Conversion from TAVR to open heart surgery was infrequently occurring in 2.5\% of the LAS group and $2.9 \%$ of the GA group, without any significant difference between the groups.

The main reasons for conversion from LAS to GA were vascular and procedural complications, hypotension, respiratory complications and insufficient patient compliance or patient discomfort.

The meta-analysis did not reveal a significant difference between the groups in the rate complications such as major and minor vascular complications, major and life-threatening bleeding, acute kidney injury, myocardial infarctions and stroke.

Only three studies reported a slightly lower frequency of pneumonia in LAS group, but the difference between the two groups did not reach statistical significance. It is possible to speculate that this tendency reflects minor risk of ventilator associated pneumonia (VAP), however is not possible to better analyze this aspect because too small number of articles reported this outcome. In this review an important difference between the two groups was highlighted: the length of hospital stay was significantly shorter in the LAS group (MD - 1.49 days) and the length of intensive care unit (ICU) stay was found to be shorter for patients in the LAS group (MD 0.47 days). Since the rate of periprocedural complications is similar in both groups, such result is probably due to the time needed for the transfer of ventilated patients to the ICU, where extubation can occur with some delay after the procedure ${ }^{[28]}$.

As reported by Gauthier et al. ${ }^{[4]}$ ICU admission may be related with a nosocomial infection, with a lower risk of infectious complications for patients who received LAS for TAVR, by avoiding bladder catheterization, central venous catheter insertion and mechanical ventilation.

Another difference between the two groups was a higher rate of pacemaker (PMK) implantations in the patients who underwent LAS for TAVR occurring in $17.5 \%$ of patients compared with $12.8 \%$ of the GA group.

A third-degree atrioventricular block is a frequent periprocedural complication requiring a PMK. This result may be due to increased patient movement during valve positioning because of discomfort or poor patient compliance. In some case has been also reported an anxiogenic effect due to decreased cerebral blood flow during rapid ventricular pacing ${ }^{[37]}$. Furthermore, the use of GA eases precise valve positioning thanks to a short interruption of mechanical ventilation and patient immobility.

\section{DISCUSSION}

Analyzing international literature, it appears clear that both anesthesiologic techniques GA and LAS are safe and none of them influence negatively the patient outcome.

From many studies a new trend towards minimally invasive anesthesia for TAVR has emerged, especially regarding the TF approach which is the most used technique for TAVR. The choice of anesthetic management generally depends on the patient's clinical profile and the procedural technical characteristics, but a center's experience and internal organization also play an important role in the decision-making. When a TAVR program starts, many operators might choose to perform the procedure with GA because of the uncertainty of a new procedure, initial low volume, operator's learning curve and the possible complications more frequent in centers with low volume of $\mathrm{TAVR}^{[48]}$. As the learning curve of the operators reaches a new plateau and the techniques of TAVR evolve, the procedure time becomes shorter and the complications decrease; this needs around two years of continuous activity or 50 consecutive cases ${ }^{[48]}$. Others revealed a learning curve with an improvement in complications rate, after the initial 86 cases using 
the Edwards valve and 40 cases using the CoreValve ${ }^{[49]}$. Due to this improvement in the procedure time and complications rate, the care team should be able to perform safely LAS for patients undergoing TAVR. Although minimal invasive anesthesiologic management is always more widespread, in some clinical situations could be advantageous provide TAVR under GA. This is particularly true in patients unable to maintain adequate immobility throughout the procedure. This may include patients with neurological impairment and patients with advanced heart failure with pulmonary edema that impede to keep supine position for prolonged periods of time. Even if TEE can used also under sedation, the planned use of TEE may necessitate GA, because of long time esophageal stimulation. The general opinion is that TEE can help during valve deployment and in rapid identification of complications; nevertheless, its routine use may not be justified.

A further clinical situation in with providing GA may be safer than LAS is when patient is expected to be at high risk for intraprocedural complications because of anatomic conformation.

Prevention of these complications should be based on patient screening and selection by a dedicated "heart team". In such cases, the use of multimodality imaging may play an even more important role, with the aim to evaluate patient suitability for the proposed access site and to select prosthesis size based on aortic measurement. Preprocedural program is also useful to ensure if proposed device can be safely deployed, based on device characteristics and the anatomic relationships between the aortic valve and root, left ventricle and coronary ostia ${ }^{[50]}$. As experience suggests, if pre-procedural evaluation estimates that there might be a mechanical complication, GA is recommended rather than sedation. The same management is recommended for patient with difficult airway management because, in case of emergency conversion from LAS to GA, any delay in endotracheal intubation may be unsafe.

Another important consideration in management of patients undergoing TAVR should be considered: over the last decade, TAVR has emerged to become the preferred alternative for high-risk patients with severe aortic symptomatic stenosis. Nevertheless, new perspective seems destined to expand indications for TAVI towards lower risk, younger and asymptomatic populations ${ }^{[51,52]}$. In such a case, a less invasive strategy, using LAS instead of GA, seems to be even more appropriate in order to make TAVR procedure even safer, faster, with fewer risks and to achieve a easier post-operative management.

\section{CONCLUSION}

Preoperative anesthesiologic management should be based on the experience of the team, preferring GA in the initial phases of the program (about 50 cases). Selection of anesthetic technique should be individualized on the patient's clinical status, preferring GA in case of difficult airway and in case of predicted technical difficulty. Instead, patients with advanced respiratory disease or renal impairment or patients with high risk in developing delirium after GA, should be treated by LAS.

Whether the team provide GA or LAS, the hybrid operating room must be equipped with devices for managing difficult airways and emergency scenarios. Also, there is an agreement that anesthesiologists involved in performing TAVR must be part of a "heart team", who must be confident with anesthesia for cardiovascular surgery, with mechanical circulatory support, and with TEE.

\section{DECLARATIONS}

\section{Authors' contributions}

Concept, drafting, data collection, final approval: Candela C, Di Pumpo A

Critical revision, final approval: Centonze A, Cucciniello F 
Supervision, critical revision, final approval: Sarubbi D, Agrò FE

Availability of data and materials

Not applicable.

\section{Financial support and sponsorship}

None.

\section{Conflicts of interest}

All authors declared that there are no conflicts of interest.

\section{Ethical approval and consent to participate}

Not applicable.

\section{Consent for publication}

Not applicable.

\section{Copyright}

(c) The Author(s) 2018.

\section{REFERENCES}

1. Iung B, Baron G, Butchart EG, Delahaye F, Gohlke-Bärwolf C, Levang OW, Tornos P, Vanoverschelde JL, Vermeer F, Boersma E, Ravaud P, Vahanian A. A prospective survey of patients with valvular heart disease in Europe: the euro heart survey on valvular heart disease. Eur Heart J 2003;24:1231-43.

2. Oppizzi M. Echocardiography in the perioperative decision making of patients with aortic stenosis. HSR Proc Intensive Care Cardiovasc Anesth 2009;1:7-15.

3. Carabello BA, Paulus WJ. Aortic stenosis. Lancet 2009;373:956-66.

4. Cribier A, Eltchaninoff H, Bash A, Borenstein N, Tron C, Bauer F, Derumeaux G, Anselme F, Laborde F, Leon MB. Percutaneous transcatheter implantation of an aortic valve prosthesis for calcific aortic stenosis: first human case description. Circulation 2002;106:3006-8.

5. Nishimura RA, Otto CM, Bonow RO, Carabello BA, Erwin JP 3rd, Guyton RA, O’Gara PT, Ruiz CE, Skubas NJ, Sorajja P, Sundt TM 3rd, Thomas JD; ACC/AHA Task Force Members. 2014 AHA/ACC guideline for the management of patients with valvular heart disease: executive summary: a report of the American College of Cardiology/American heart association task force on practice guidelines. Circulation 2014;129:2440-92.

6. Webb JG, Wood DA. Current status of transcatheter aortic valve replacement. J Am Coll Cardiol 2012;60:483-92.

7. Leon MB, Kodali S, Williams M, Oz M, Smith C, Stewart A, Schwartz A, Collins M, Moses JW. Transcatheter aortic valve replacement in patients with critical aortic stenosis: rationale, device descriptions, early clinical experiences, and perspectives. Semin Thorac Cardiovasc Surg 2006;18:165-74.

8. Latsios G, Gerckens U, Grube E. Transaortic transcatheter aortic valve implantation: a novel approach for the truly "no-access option" patients. Catheter Cardiovasc Interv 2010;75:1129-36.

9. Johansson M, Nozohoor S, Kimblad PO, Harnek J, Olivecrona GK, Sjögren J. Transapical versus transfemoral aortic valve implantation: a comparison of survival and safety. Ann Thorac Surg 2011;91:57-63.

10. Moynagh AM, Scott DJ, Baumbach A, Khavandi A, Brecker SJ, Laborde JC, Brown S, Chowdhary S, Saravanan D, Crean PA, Teehan S, Hildick-Smith D, Trivedi U, Khogali SS, Bhabra MS, Roberts DH, Morgan KP, Blackman DJ; UK CoreValve Collaborative. CoreValve transcatheter aortic valve implantation via the subclavian artery: comparison with the transfemoral approach. J Am Coll Cardiol 2011;57:634-5.

11. Mack MJ, Brennan JM, Brindis R, Carroll J, Edwards F, Grover F, Shahian D, Tuzcu EM, Peterson ED, Rumsfeld JS, Hewitt K, Shewan C, Michaels J, Christensen B, Christian A, O’Brien S, Holmes D; STS/ACC TVT Registry. Outcomes following transcatheter aortic valve replacement in the United States. JAMA 2013;310:2069-77.

12. Greenbaum AB, O’Neill WW, Paone G, Guerrero ME, Wyman JF, Cooper RL, Lederman RJ. Caval-aortic access to allow transcatheter aortic valve replacement in otherwise ineligible patients: initial human experience. J Am Coll Cardiol 2014;63:2795-804.

13. Mylotte D, Sudre A, Teiger E, Obadia JF, Lee M, Spence M, Khamis H, Al Nooryani A, Delhaye C, Amr G, Koussa M, Debry N, Piazza N, Modine T. Transcarotid transcatheter aortic valve replacement: feasibility and safety. JACC Cardiovasc Interv 2016;9:472-80.

14. Ree RM, Bowering JB, Schwarz SK. Case series: anesthesia for retrograde percutaneous aortic valve replacement--experience with the first 40 patients. Can J Anaesth 2008;55:761-8. 
15. Behan M, Haworth P, Hutchinson N, Trivedi U, Laborde JC, Hildick-Smith D. Percutaneous aortic valve implants under sedation: our initial experience. Catheter Cardiovasc Interv 2008;72:1012-5.

16. Billings FT 4th, Kodali SK, Shanewise JS. Transcatheter aortic valve implantation: anesthetic considerations. Anesth Analg 2009; 108:1453-62.

17. Basciani RM, Eberle B. Percutaneous aortic valve implants under sedation: our initial experience. Catheter Cardiovasc Interv 2009; 74:148-9.

18. Sellevold OF, Guarracino F. Transcutaneous aortic valve implantation: recent advances and future. Curr Opin Anaesthesiol 2010;23:6773.

19. Guarracino F, Landoni G. Con: transcatheter aortic valve implantation should not be performed under general anesthesia. J Cardiothorac Vasc Anesth 2012;26:736-9.

20. Motloch LJ, Rottlaender D, Reda S, Larbig R, Bruns M, Müller-Ehmsen J, Strauch J, Madershahian N, Erdmann E, Wahlers T, Hoppe UC. Local versus general anesthesia for transfemoral aortic valve implantation. Clin Res Cardiol 2012;101:45-53.

21. Brecker SJ, Bleiziffer S, Bosmans J, Gerckens U, Tamburino C, Wenaweser P, Linke A; ADVANCE Study Investigators. Impact of anesthesia type on outcomes of transcatheter aortic valve implantation (from the multicenter ADVANCE study). Am J Cardiol 2016;117:1332-8.

22. Tritapepe L, Landoni G, Guarracino F, Pompei F, Crivellari M, Maselli D, De Luca M, Fochi O, D’Avolio S, Bignami E, Calabrò MG, Zangrillo A. Cardiac protection by volatile anaesthetics: a multicentre randomized controlled study in patients undergoing coronary artery bypass grafting with cardiopulmonary bypass. Eur J Anaesthesiol 2007;24:323-31.

23. Bignami E, Biondi-Zoccai G, Landoni G, Fochi O, Testa V, Sheiban I, Giunta F, Zangrillo A. Volatile anesthetics reduce mortality in cardiac surgery. J Cardiothorac Vasc Anesth 2009;23:594-9.

24. Landoni G, Fochi O, Tritapepe L, Guarracino F, Belloni I, Bignami E, Zangrillo A. Cardiac protection by volatile anesthetics. A review. Minerva Anestesiol 2009;75:269-73.

25. De Hert SG, Turani F, Mathur S, Stowe DF. Cardioprotection with volatile anesthetics: mechanisms and clinical implications. Anesth Analg 2005;100:1584-93.

26. Chiari P, Bouvet F, Piriou V. Anaesthetic-induced myocardial preconditioning: fundamental basis and clinical implications. Ann Fr Anesth Reanim 2005;24:383-96.

27. Petronio AS, Giannini C, De Carlo M, Bedogni F, Colombo A, Tamburino C, Klugmann S, Poli A, Guarracino F, Barbanti M, Latib A, Brambilla N, Fiorina C, Bruschi G, Martina P, Ettori F. Anaesthetic management of transcatheter aortic valve implantation: results from the Italian CoreValve registry. EuroIntervention 2016;12:381-8.

28. Goren O, Finkelstein A, Gluch A, Sheinberg N, Dery E, Matot I. Sedation or general anesthesia for patients undergoing transcatheter aortic valve implantation--does it affect outcome? An observational single-center study. J Clin Anesth 2015;27:385-90.

29. Wiegerinck EM, Boerlage-van Dijk K, Koch KT, Yong ZY, Vis MM, Planken RN, Eberl S, de Mol BA, Piek JJ, Tijssen JG, Baan J Jr. Towards minimally invasiveness: transcatheter aortic valve implantation under local analgesia exclusively. Int J Cardiol 2014;176:10502.

30. Piayda KD, Gafoor S, Bertog S, Doss M, Vaskelyte L, Matic P, Franke J, Hofmann I, Staiger N, Reinartz M, Sievert H. True first-line local-anesthesia only protocol for transfemoral TAVI. J Invasive Cardiol 2015;27:501-8.

31. Durand E, Borz B, Godin M, Tron C, Litzler PY, Bessou JP, Bejar K, Fraccaro C, Sanchez-Giron C, Dacher JN, Bauer F, Cribier A, Eltchaninoff H. Transfemoral aortic valve replacement with the Edwards SAPIEN and Edwards SAPIEN XT prosthesis using exclusively local anesthesia and fluoroscopic guidance: feasibility and 30-day outcomes. JACC Cardiovasc Interv 2012;5:461-7.

32. Yamamoto M, Meguro K, Mouillet G, Bergoend E, Monin JL, Lim P, Dubois-Rande JL, Teiger E. Effect of local anesthetic management with conscious sedation in patients undergoing transcatheter aortic valve implantation. Am J Cardiol 2013;111:94-9.

33. Chin D. Echocardiography for transcatheter aortic valve implantation. Eur J Echocardiogr 2009;10:i21-9.

34. Gonçalves A, Marcos-Alberca P, Zamorano JL. Echocardiography: guidance during valve implantation. EuroIntervention 2010;6:G149.

35. Bufton KA, Augoustides JG, Cobey FC. Anesthesia for transfemoral aortic valve replacement in North America and Europe. J Cardiothorac Vasc Anesth 2013;27:46-9.

36. Park HS, Kim KM, Joung KW, Choi IC, Sim JY. Monitored anesthesia care with dexmedetomidine in transfemoral percutaneous transcatheter aortic valve implantation: two cases report. Korean J Anesthesiol 2014;66:317-21.

37. Dehédin B, Guinot PG, Ibrahim H, Allou N, Provenchère S, Dilly MP, Vahanian A, Himbert D, Brochet E, Radu C, Nataf P, Montravers P, Longrois D, Depoix JP. Anesthesia and perioperative management of patients who undergo transfemoral transcatheter aortic valve implantation: an observational study of general versus local/regional anesthesia in 125 consecutive patients. J Cardiothorac Vasc Anesth 2011;25:1036-43.

38. Ben-Dor I, Looser PM, Maluenda G, Weddington TC, Kambouris NG, Barbash IM, Hauville C, Okubagzi P, Corso PJ, Satler LF, Pichard AD, Waksman R. Transcatheter aortic valve replacement under monitored anesthesia care versus general anesthesia with intubation. Cardiovasc Revasc Med 2012;13:207-10.

39. Babaliaros V, Devireddy C, Lerakis S, Leonardi R, Iturra SA, Mavromatis K, Leshnower BG, Guyton RA, Kanitkar M, Keegan P, Simone A, Stewart JP, Ghasemzadeh N, Block P, Thourani VH. Comparison of transfemoral transcatheter aortic valve replacement performed in the catheterization laboratory (minimalist approach) versus hybrid operating room (standard approach): outcomes and cost analysis. JACC Cardiovasc Interv 2014;7:898-904.

40. Watterson LM, Morris RW, Westhorpe RN, Williamson JA. Crisis management during anaesthesia: bradycardia. Qual Saf Health Care 
2005;14:e9.

41. Morris RW, Watterson LM, Westhorpe RN, Webb RK. Crisis management during anaesthesia: hypotension. Qual Saf Health Care 2005; 14:e11.

42. Abawi M, Nijhoff F, Agostoni P, Emmelot-Vonk MH, de Vries R, Doevendans PA, Stella PR. Incidence, predictive factors, and effect of delirium after transcatheter aortic valve replacement. JACC Cardiovasc Interv 2016;9:160-8.

43. Oguri A, Yamamoto M, Mouillet G, Gilard M, Laskar M, Eltchaninoff H, Fajadet J, Iung B, Donzeau-Gouge P, Leprince P, Leguerrier A, Prat A, Lievre M, Chevreul K, Dubois-Rande JL, Chopard R, Van Belle E, Otsuka T, Teiger E; FRANCE 2 Registry Investigators. Clinical outcomes and safety of transfemoral aortic valve implantation under general versus local anesthesia: subanalysis of the French Aortic National CoreValve and Edwards 2 registry. Circ Cardiovasc Interv 2014;7:602-10.

44. Wöhrle J, Gonska B, Rodewald C, Seeger J, Scharnbeck D, Rottbauer W. Transfemoral aortic valve implantation with the new Edwards Sapien 3 valve for treatment of severeaortic stenosis-impact of valve size in a single center experience. PLoS One 2016;11:e0151247.

45. Kodali S, Thourani VH, White J, Malaisrie SC, Lim S, Greason KL, Williams M, Guerrero M, Eisenhauer AC, Kapadia S, Kereiakes DJ, Herrmann HC, Babaliaros V, Szeto WY, Hahn RT, Pibarot P, Weissman NJ, Leipsic J, Blanke P, Whisenant BK, Suri RM, Makkar RR, Ayele GM, Svensson LG, Webb JG, Mack MJ, Smith CR, Leon MB. Early clinical and echocardiographic outcomes after SAPIEN 3 transcatheter aortic valve replacement in inoperable, high-risk and intermediate-risk patients with aortic stenosis. Eur Heart J 2016;37:2252-62.

46. Ehret C, Rossaint R, Foldenauer AC, Stoppe C, Stevanovic A, Dohms K, Hein M, Schälte G. Is local anaesthesia a favourable approach for transcatheter aortic valve implantation? A systematic review and meta-analysis comparing local and general anaesthesia. BMJ Open 2017;7:e16321.

47. Gauthier C, Astarci P, Baele P, Matta A, Kahn D, Kefer J, Momeni M. Mid-term survival after transcatheter aortic valve implantation: results with respect to the anesthetic management and to the access route (transfemoral versus transapical). Ann Card Anaesth $2015 ; 18: 343-51$

48. Lunardi M, Pesarini G, Zivelonghi C, Piccoli A, Geremia G, Ariotti S, Rossi A, Gambaro A, Gottin L, Faggian G, Vassanelli C, Ribichini F. Clinical outcomes of transcatheter aortic valve implantation: from learning curve to proficiency. Open Heart 2016;3:e000420.

49. Arai T, Lefèvre T, Hovasse T, Hayashida K, Watanabe Y, O'Connor SA, Benamer H, Garot P, Cormier B, Bouvier E, Morice MC, Chevalier B. Evaluation of the learning curve for transcatheter aortic valve implantation via the transfemoral approach. Int J Cardiol 2016;203:491-7.

50. Bloomfield GS, Gillam LD, Hahn RT, Kapadia S, Leipsic J, Lerakis S, Tuzcu M, Douglas PS. A practical guide to multimodality imaging of transcatheter aortic valve replacement. JACC Cardiovasc Imaging 2012;5:441-55.

51. Arora S, Vavalle JP. Transcatheter aortic valve replacement in intermediate and low risk patients-clinical evidence. Ann Cardiothorac Surg 2017;6:493-7.

52. Hamm CW, Arsalan M, Mack MJ. The future of transcatheter aortic valve implantation. Eur Heart J 2016;37:803-10. 